\title{
Overweight and Obesity among School Children
}

\author{
Vitorino Modesto dos Santos' (D), Laura Campos Modesto² (ID) \\ 'Department of Medicine, Armed Forces Hospital and Catholic University of Brasilia-DF, Brasilia-DF, Brazil \\ ${ }^{2}$ Medical Course at the University Center of Brasilia (Uniceub), Brasília-DF, Brazil
}

ORCID iDs of the authors: V.M.S. 0000-0002-7033-6074; L.C.M. 0000-0002-940I-2277.

Cite this article as: dos Santos, VM, Modesto LC. Overweight and Obesity among School Children. Cyprus J Med Sci 2021 ; 6(2): 183-184.

\section{Dear Editor,}

Despite the significant ethnic differences, the prevalence of overweight and obesity in primary school students is a serious public health problem in Cyprus, Turkey, and Brazil. ${ }^{1-4}$ Excess of body weight has been a global burden associated with metabolic and cardiovascular disorders with a significant reflex in both the quality and expectancy of life in adulthood. ${ }^{\text {-4 }}$ Health policies must control and reduce the "overweight and obesity pandemic" across the world. Comparisons among data of some studies developed in school children of Cyprian and Brazilian populations between 2004 and 2019 seem useful to know about the modified parameters.

Lazarou et al. ${ }^{2}$ evaluated II40 children aged between 9 and 13 years with a mean age of 10.7 years, in which 177 boys and 23I girls were obese [p: .004], whereas 187 boys and 259 girls had overweight [p: .177]. The authors found a correlation of obesity with screen viewing time, mainly among girls, and emphasized interventions to avoid sedentary behaviors in this young Cyprian population. ${ }^{2}$ More recently, Arikan et al.' studied the body mass index of $10,78 \mathrm{I}$ students from 16 primary schools of Konya city center in Turkey. They were aged between 6 and 15 years, in which $52 \%$ were boys. Also, they found that $5.8 \%$ of overall prevalence of obesity were among boys and $5.3 \%$ among girls, while $7.4 \%$ of overall prevalence of overweight occurred in individuals of both genders.' The authors suggested new studies to define the best strategies for weight control in childhood. Xavier et al. ${ }^{4}$ evaluated 229 Brazilian students aged between 5 and 15 years with a mean age of 8.0 years, in which $51.5 \%$ were girls, and found that the prevalence of overweight and obesity was $11.8 \%$ and $13.5 \%$, respectively. There was no significant difference in the data between the gender and age groups of students. Weight gain showed a nonstatistical association with television viewing time for more than two hours daily; however, there was no relation between physical inactivity or screen viewing time and obesity. The authors commented on the role of parents and healthcare workers in preventive tasks. ${ }^{4}$ Pereira et al. ${ }^{3}$ investigated weight gain and high blood pressure (HBP) in 888 Brazilian students aged between 6 and 10 years with a mean age of 7.7 years, in which $51.7 \%$ were girls, and found that the prevalence of overweight and obesity were $17.7 \%$ and $16.2 \%$, respectively. Obesity was associated with HBP, even after adjusting gender, ie, $43.6 \%$ in the $6-7$ years old group and $62.9 \%$ in the 8 9 years-old group. There was no significant difference in the variables between the gender and age groups of students. $^{4}$

The commented manuscripts highlighted the requirement of preventive programs including weight excess and arterial hypertension among school children.

Peer-review: Externally peer-reviewed.

Author contributions: Concept - V.M.S., L.C.M.; Design - V.M.S., L.C.M.; Data Collection and/or Processing - V.M.S., L.C.M.; Analysis and/or Interpretation - V.M.S., L.C.M.; Writing - V.M.S., L.C.M.

Conflict of Interest: The authors have no conflicts of interest to declare.

Financial Disclosure: The authors declared that this study has received no financial support. 


\section{REFERENCES}

I. Arıkan Ş, Kamuk YU, Revan S. The prevalence of overweight and obesity among students between the ages of 6 and 15 years in Konya. Cyprus J Med Sci. 2020;5(3):234-238. [CrossRef]

2. Lazarou C, Soteriades ES. Children's physical activity, TV watching and obesity in Cyprus: The CYKIDS study. Eur J Public Health. 2010;20(I):70-77. [CrossRef]
3. Pereira FEF, Teixeira FDC, Kac G, Soares EA, Ribeiro BG. Overweight and obesity associated with high blood pressure: A crosssectional study in Brazilian students. Rev Esc Enferm USP. 2020;54:e03654. [CrossRef]

4. Xavier MM, Xavier RM, Magalhães FO, Nunes AA, Santos VM. Factors associated with the prevalence of overweight in school children. Pediatr Mod. 2009;45(3):105-108. 